\title{
Prediction Skills and Its Influence on Learners' Achievement in Reading Comprehension: A Case of Vihiga County, Kenya
}

\author{
Mary Susan Anyiendah, Paul Odundo and Agnes Kibuyi \\ University of Nairobi, Nairobi, Kenya
}

\begin{abstract}
Prediction is one of the comprehension processing skills encapsulated by the interactive approach instruction. Prediction skills enable learners to decode the meaning of comprehension passages by making guesses about the contents of texts to be read. Learners in Vihiga County perform poorer in English language examinations than their peers in neighbouring counties. The performance is weaker in comprehension than in grammar sections. Despite this, no study has assessed the nexus between the use of prediction skills and learners' achievement in reading comprehension. This study applied the Solomon Four-Group Design to obtain primary data from 279 primary school learners and eight teachers in 2017. Multiple Linear Regression was used to generate two models, one for the experimental group (Model 1) and one for the control group (Model 2). Results show that the influence of prediction skills on learners' achievement in reading comprehension was statistically significant the experimental group, but insignificant in the control group. However, the influence seemed to be stronger in the experimental than in the control group, which suggests that training English language teachers on how to correctly apply prediction skills is likely to improve learners' achievement in reading comprehension. The study recommends the need to: sensitise teachers to use textbooks cautiously, while supplementing with relevant resource materials; sensitise teachers on the need to guide learners through titles; as well as update the teacher training curriculum by integrating inter alia, new instructional methods based on information and communication technology and entrenching innovation to enable teachers diversify instructional resources.
\end{abstract}

Keywords: learners, prediction skills, interactive approach, instruction, comprehension, reading, Vihiga County

\section{Introduction}

In Kenya, the official education policy sets English language as the medium of general and academic instruction, learning and evaluation processes in the basic education system (Roy-Campbell, 2014). More overtly, the National Commission on Educational Objectives and Policies of 1976 (the Gachathi Commission) recommended that English language be introduced as a subject for the first three years of primary education, and as the medium of instruction in Class Four going upwards (Mose, 2017; Oluoch, 2017; Roy-Campbell, 2014). Despite this, most primary schools begin instructing their learners using English language from Class One because they know that language competency is essential for high academic achievement in upper primary (Gathumbi, 2008, as cited in Roy-Campbell, 2014). Studies conducted separately by Finney (2013) and Vries

Mary Susan Anyiendah, Ph.D. candidate, Department of Educational Communication \& Technology, University of Nairobi, Nairobi, Kenya.

Paul Odundo, professor, Department of Educational Communication \& Technology, University of Nairobi, Nairobi, Kenya.

Agnes Kibuyi, Professor, Department of Educational Communication \& Technology, University of Nairobi, Nairobi, Kenya. 
(2011) confirmed that learners' proficiency in written and spoken English is critical for their performance in all the subjects taught and examined using the language.

Reading is one of the ways through which learners improve their aptitude in English language. As cited in Amartha (2013), Wolfe (2004) described reading as a process of decoding and comprehending written text or symbols. Whereas decoding involves identifying and connecting letter strings to corresponding units of speech that they represent in order to make sense of texts or symbols, comprehension entails higher-order cognitive and linguistic reasoning, which allow learners to extract and construct the meaning of written language or symbols (Amartha, 2013). This is achieved when readers interact with written matter, makes speculative conjectures about the meaning of texts and decodes the meaning of such to either confirm or negate their conjectures. This makes reading an active process that goes beyond identification of written matter to establishing the meaning of such in isolation and in context (Palani, 2012). The extent to which readers interact with texts and correctly predicts the meaning of words used depends on individual's cognitive knacks. However, the type of instructional methods applied by teachers seem to play a greater role in influencing and motivating learners to engage with English text passages in order to improve their comprehension skills. Such skills are essential for learners' understanding, interpretation, and response to examination questions (Anyiendah \& Odundo, 2017).

The interactive approach instruction stands out in extant literature as one of the effective methods used by teachers to encourage learners' interaction with texts, as well as activate their comprehension processing skills and ability to construct the meaning of written language or symbols (Nur \& Ahmad, 2017; Amartha, 2013; Hudson, 2007). In this regard, studies conducted in various contexts have proved that learners instructed using the interactive approach demonstrate outstanding dexterity in decoding the meaning of words used in comprehension passages, predicting the meaning of texts, summarising huge texts without changing or losing the original meaning, connecting texts to their background knowledge, as well as generating questions and answers on the subject of texts (Nur \& Ahmad, 2017; Amartha, 2013; Harmer, 1983).

Prediction is one of the comprehension processing skills forming the interactive approach instruction (Nur \& Ahmad, 2017; Oczkus, 2013; Rokhsari, 2012). Learners need prediction skills in order to understand text passages and improve their performance in reading comprehension. Application of prediction skills in reading entails instructing learners to make guesses about the meaning of texts before reading, and then comparing their predictions with actual contents of such texts (Nur \& Ahmad, 2017). In view of this, readers are trained to relate what they already know with the content of comprehension passages (Rokhsari, 2012). When applying prediction skills, teachers and learners deploy various strategies, either in isolation or conjointly, depending on the nature of the comprehension passage. The strategies include use of pictures, titles, visualisation and anticipation guides (Oczkus, 2013; Rokhsari, 2012).

Pictures and titles are effective in facilitating young learners' ability to recall key messages and provide answers specific questions related to the comprehension subject. More still, visualisation requires teachers to assist learners to develop images of stories in their mind as they read. This enables them to recall what they have read and connect that to real life situations. The accuracy of such mental images depends on how well learners' reading skills have been developed. The accuracy also improves as learners' knowledge of the subject deepens and broadens (Oczkus, 2013; Palincsar, Spiro, \& Magnusson, 2013). Learners' prediction skills are further enhanced through the use of anticipation guides. In this case, teachers instruct learners to read pre-selected statements concerning the subject at hand, before reading comprehension passages. At the end of 
the reading task, learners are taken through each statement in the anticipation guide. They are instructed to make decisions by either agreeing or disagreeing with the statements, based on the insights obtained from comprehension passages (Oczkus, 2013; Palincsar et al., 2013).

The relationship between interactive approach instruction and learners' academic performance is a subject that has been studied extensively across the globe. Analysis of such studies reveals two broad categories: general and specific literature. General literature includes studies that examined the relationship between the interactive approach instruction and learners' overall academic performance. Examples of such studies include Finney (2013), Vries (2011), Redfern and Edwards (2007) as well as Akbar and Majid (2011), among others. Specific literature includes studies that examined the relationship between specific aspects of the interactive approach instruction, such as prediction skills, and learners' performance in reading comprehension. Examples of such studies include Smith (2009), Hibbing and Rankin-Erickson (2003), Pressley and Gaskins (2006), as well as Dubeck, Jukes, and Okello (2012), among others.

In Kenya, various studies have examined the relationship between learners' performance in examinations, with the aim of determining factors contributing to poor performance at the institutional, sub-county, county and national levels (Ongatoh, 2017; Kathuri, 2014; Uwezo, 2012; Isutsa, 2011). An important finding that runs through most of the studies is the correlation between the type of instructional methods used by teachers and learners' performance. More specifically, "poor instructional methods" is one of the factors contributing to learners' sub-optimal performance in national examinations. This was separately reported by studies conducted by Ongatoh (2017), Kathuri (2014) and Isutsa (2011). "Incorrect instructional methods" was also identified by Uwezo (2012), as a pervasive and perpetual challenge affecting learners' performance in reading comprehension passages. As a result, only one-third (32\%) of standard six pupils could read a standard-two-level passage in English (Uwezo, 2012).

A few other studies, such as Commeyras and Inyega (2007), have investigated the relationship between the interactive approach instruction and learners' academic performance, while others, such as Dubeck et al. (2012), as well as Makokha and Wanyonyi (2015), have delved into the connection between prediction skills and learners performance in reading comprehension. More specifically, Commeyras and Inyega (2007) reported that even though one-third of teachers applied the interactive approach in comprehension reading lessons, observations revealed that in about $90 \%$ of the lessons, the method was applied incorrectly. Consequently, incorrect application of the interactive approach instruction emerged as a key factor influencing learners' performance in reading comprehension. In their study, Dubeck et al. (2012) reported a significant correlation between the frequency with which teachers apply prediction skills and learners' scores in post-reading questions. A significant association between the frequency with which teachers use prediction in reading and learners scores in post-reading tests was also reported by Makokha and Wanyonyi (2015).

Vihiga County is located in the Western region of Kenya between longitudes $34^{\circ} 30^{\prime}$ and $35^{\circ} 0^{\prime} \mathrm{E}$ and latitudes $0^{\circ}$ and $0^{\circ} 15^{\prime} \mathrm{N}$ (County Government of Vihiga, 2018). It neighbours Kisumu County to the South, Siaya and Busia Counties to the West, Kakamega County to the North and Nandi County to the East. A snapshot of Kenya National Examination Council (KNEC) results for the period 2011 to 2014 reveals that the county's performance in the English language paper of Kenya Certificate of Primary Education (KCPE) has persistently remained lower compared to that of its neighbours, such as Kisumu, Kakamega and Busia (KNEC, 2011; 2012; 2013; 2014), as illustrated by Figure 1. 


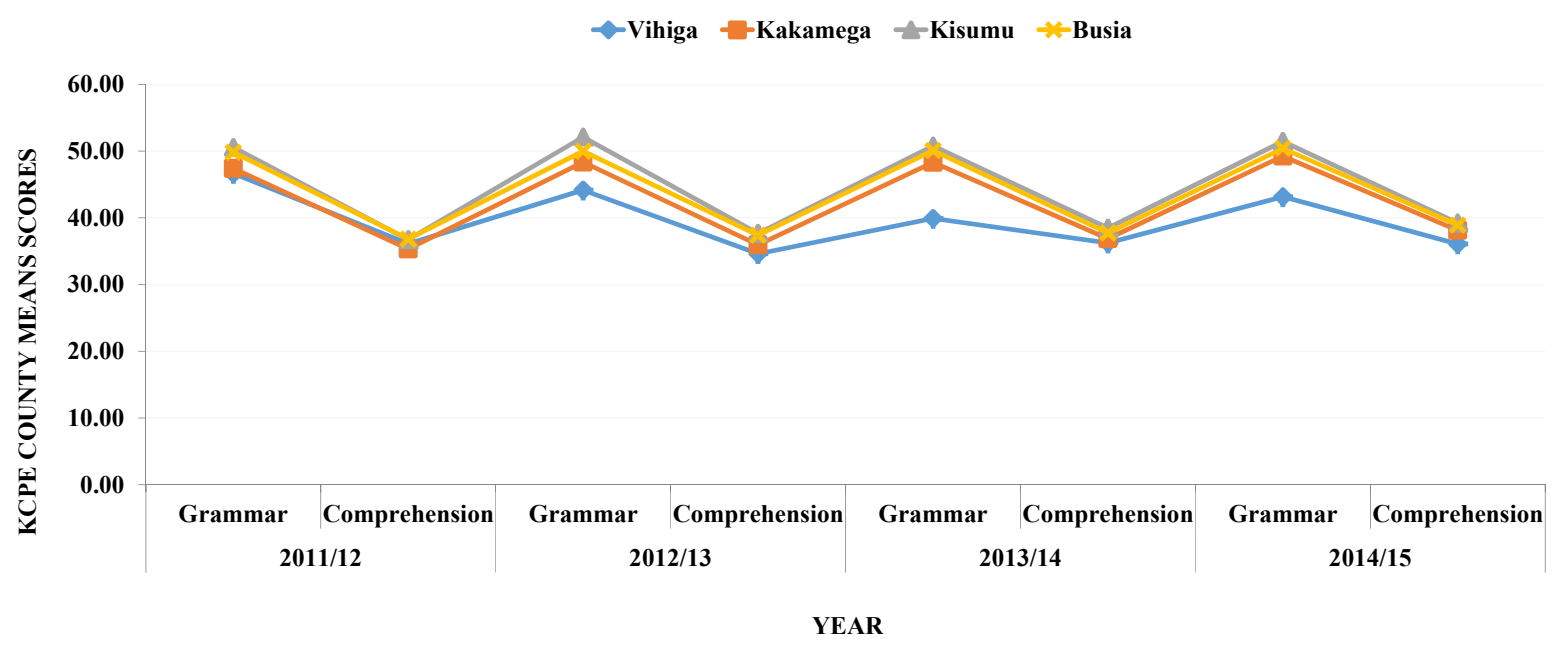

Figure 1. Learners' performance in the KCPE English language (Source: KNEC Annual Reports 2011-2014).

More nauseatingly, Figure 1 shows that the learners' performance in the English language examinations remains relatively lower in the comprehension section than in the grammar section (KNEC, 2011; 2012; 2013; 2014). These two issues have captured the attention of education stakeholders in Vihiga County, including government agencies at the national and county levels, non-state actors, school administrations, parents and education policy researchers, among others. A review of existing literature reveals that no academic study has examined the relationship between the interactive approach instruction and learners' achievement in reading comprehension in Vihiga County. Consequently, the dearth of information that would inform policy, support and facilitative interventions, needs no emphasis.

By responding to the stated gap, this study was expected to generate information that would inform policy and programming processes focused creating opportunities for English language teachers to access training on the interactive approach instruction. The findings were further expected to enthuse further research on the subject, not only in Kenya, but also in other developing countries. Even though the study covered all the five aspects of the interactive approach instruction, including background knowledge, learner-generated questions, summarisation, prediction and word recognition skills, this article concentrates on the connexion between prediction skills and learners' achievement in reading comprehension.

\section{Literature Review}

Reading is the process of identifying, extracting and constructing the meaning of written language or symbols. This is achieved when readers generate pertinent conjectures on the content of texts before reading, and confirming such conjectures during or at the end of the reading task (Nur \& Ahmad, 2017; Amartha, 2013). Reading is also the foremost process through which learners improve their proficiency in English language. In Kenya, where English is the official language for curriculum delivery in the basic education system, learners' competency in reading is an essential requirement for good performance in all subjects anchored on the language (Finney, 2013; Vries, 2011; Cox, 2009). Consequently, learners with poor reading skills often find it difficult to cope with the reading demands in other subjects, while those with excellent reading skills are quick to adjust to reading tasks in non-lingual subjects. Finney (2013), Akbar and Majid (2011), and Vries (2011), separately, described the interactive approach instruction as an effective method for developing learners' 
comprehension reading skills, and as such, Finney (2013) believed it plays an important role in learners' overall academic achievement in all subjects instructed using the English language.

The interactive approach instruction is an amalgam model that leverages on strengths of the classical bottom-up and top-down reading approaches (Sharpe, 2013; Yan, 2002; Goodman, 1967). The model facilitates the reading process by activating essential comprehension processing skills, including background knowledge, self-generated questions, summarisation, prediction, and word recognition (Yan, 2002; Grabe, 1988). Each component of the model encourages interaction between readers and texts in the process of extracting the meaning of written language or symbols (Yan, 2002). Jointly, the five comprehension processing skills enhance readers' ability to understand written content, which is the ultimate goal of reading (Sharpe, 2013).

The causal connection between interactive approach instruction and learners' academic achievement has been investigated widely in both developed and developing countries. The resultant empirical literature can be clustered into two categories based on the content scope. The first category includes studies that examined the linkage between interactive approach instruction and learners' academic achievement; the second category includes those that examined each aspect of the interactive approach instruction, including prediction skills in relation to learners' academic achievement. This section highlights key findings reported by studies that adopted the general scope, such as Finney (2013), Vries (2011), Redfern and Edwards (2007) as well as Akbar and Majid (2011), among others. The section further explores the findings reported by studies that examined the connection between prediction skills and learners' achievement in reading comprehension, including Smith (2009), Hibbing and Rankin-Erickson (2003), Pressley and Gaskins (2006), as well as Dubeck et al. (2012), among others.

In the category of general literature, Finney (2013) established a correlation between the consistency with which US high school teachers apply the interactive approach instruction in comprehension reading lessons and learners' achievement in all subjects, including English language. In this regard, learners whose teachers applied the method consistently were more independent in reading than those whose teachers never applied the model. Further analysis of the literature reveals that the study brought to the fore the importance of consistent application of the interactive approach instruction in developing competent readers. However, the study never mentioned anything to do with the correctness of procedures for applying the interactive approach instruction.

Redfern and Edwards (2007) also found a significant statistical association between British learners' performance and the type of instructional methods applied by their teachers. In this regard, learners who were instructed using the interactive approach achieved higher scores than their colleagues who were taught using other methods. The findings led the authors to emphasise the need for comprehension reading lessons, at all relevant tiers of the education system, to be taught using the interactive approach instruction. More still, Vries (2011) established a significant correlation between the frequency with which Dutch teachers applied the interactive approach instruction and learners' performance in all subjects taught in English.

In their study, Akbar and Majid (2011) found a significant association between the use of interactive approach instruction by Indonesian teachers and learners' proficiency in reading. In this regard, the reading test scores showed that learners taught using the model obtained better results than those instructed using alternative methods. Based on this, the author concluded that the interactive approach instruction is essential for improving learners' proficiency in reading comprehension. In Pakistan, Pardhan and Juma (2011) also reported a significant association between teachers' application of the interactive approach instruction and learners' performance. In this regard, learners instructed using the interactive approach demonstrated a higher level of proficiency in decoding the content of texts than those instructed using alternative methods. 
In South Africa, Boughey (2009) conducted an experimental study, which revealed a significant difference in the mean scores obtained by learners in the experimental and those in the control group. More overtly, learners who were instructed using the interactive approach (experimental group) attained higher mean scores in comprehension questions than their colleagues in the control group. Consequently, the study suggested that teachers should be supported, facilitated, and motivated to correctly and consistently apply the interactive approach in order to improve learners' achievement in reading.

In the category of studies with specific scopes, Smith (2009) conducted a study in Australia, which established a significant reliable association between learners' application of prediction skills when reading comprehensions and their reading achievement, which was measured in terms of test scores. Besides, the influence association seemed stronger between application of prediction skills and knowledge of the scientific content. In this regard, high-knowledge learners obtained better scores than those with lower knowledge of the scientific content.

Furthermore, Hibbing and Rankin-Erickson (2003) found a significant correlation between teachers' activation of prediction skills and learners' performance in comprehension test questions. More specifically, the study established the importance of discussing titles with learners before reading passages and how such learners performed in comprehension questions. In this regard, the higher the frequency of discussing passage titles, the higher the scores obtained by struggling learners. While explaining the results, the authors observed that discussing titles before reading enabled learners to develop quick ideas, which facilitated prediction of the content and context of comprehension passages. This implies that reading achievement can be constrained for struggling learners in situations where teachers fail to discuss titles before reading comprehension passages. Doing so is important because it enables learners to connect what they know about comprehension subjects with what they expect to read about in passages.

In the United States, Pressley and Gaskins (2006) discovered that visualisation is an important strategy that can be applied consistently to activate learners' prediction skills and to improve their reading achievement. More concisely, the study underscored the role of visualisation in helping learners to process visual representations of written words, symbols or objects in order to extract meaning. Similar arguments were expressed in the report compiled by the National Reading Panel (2013). The report emphasizes the role of visualisation in motivating learners to engage with written materials, symbols or objects, while developing mental constructs of contents in subsequent sections of comprehension passages (National Reading Panel, 2013). Despite this, its application by teachers, particularly in developing countries, remains sub-optimal due to lack of relevant skills among teachers; as well as shortage of new information that would motivate and help teachers develop necessary skills.

Lubliner (2005) reported that the use of section headings caused a direct and significant influence on US high school learners' comprehension reading skills and performance. In this regard, the author observed that consistent use of section headings draws the attention of learners to the contents of various sections; making them strategic content-area readers who not only identify key messages, but also use the same to predict the contents of subsequent sections. While reviewing the study conducted by Lubliner (2005), Waller and Barrentine (2015) acknowledged that pausing and discussing section headings give learners a chance to internalise information read; thereby, facilitating their understanding of subsequent sections. This implies that when teachers fail to discuss section headings, they deny learners the opportunity to predict what is expected in subsequent sections; which constrains comprehension of text passages among struggling learners. 
In Kenya, Dubeck et al. (2012) reported that learners who always applied prediction skills when reading achieved higher scores consistently in post-reading questions than their colleagues who did so occasionally. In this regard, the study recommended that prediction skills be used as learning instruments to improve learners' performance in reading comprehension. More still, Makokha and Wanyonyi (2015) revealed that utilisation of pictures to trigger learners' prediction skills in reading was near universal. Besides, the study established a significant association between the teachers' frequency of applying prediction in reading and learners' scores in post-reading questions. Despite this, most teachers relied on pictures contained in syllabus books, with no supplementations, such as drawings, diagrams on chalkboards, or photographs. The authors singled out this as a drawback because syllabus books alone are too insufficient to help learners make accurate predictions about comprehension subjects. The authors further attributed over-reliance on book pictures to issues, such as time constraints, heavy workload, low motivation, negative school culture as well as lack of awareness and innovation, among teachers.

Studies conducted in various contexts suggest that prediction skills and learners' achievement in reading comprehension are conceptually connected, such that a unit change in learners' prediction skills is likely to influence a proportionate change in their achievement in post-reading tests Notably though, none of such studies focused on the situation in Vihiga County, Kenya. Arising from this challenge, the investigator developed the conceptual framework that is presented in Figure 2. The framework elaborates the investigator's perception regarding the causal relationship between learners' prediction skills and their achievement in reading comprehension. In this regard, prediction skills was set as the independent variable, while learners' achievement in reading comprehension was designated the dependent variable. The independent variable was unpacked using five perception statements, which aligned to specific reading practices that demonstrate learners' prediction skills. Besides, each perception statement was measured using a five-point scale, marked as "strongly agree", "agree", "undecided", "disagree", and "strong disagree".

\begin{tabular}{|c|c|c|}
\hline Independent variable & Moderating variables & Dependent variable \\
\hline $\begin{array}{l}\quad \text { Prediction skills } \\
\text {-I try to visualize information to } \\
\text { help me remember what I read. } \\
\text {-I try to guess what the material is } \\
\text { all about when I read the } \\
\text { information. }\end{array}$ & $\begin{array}{l}\text { Learners' attributes } \\
\text {-Age } \\
\text {-Gender } \\
\text {-School } \\
\text {-Sub-group }\end{array}$ & $\begin{array}{l}\frac{\text { Achievement in reading }}{\text { comprehension }} \\
\text {-Performance in } \\
\text { post-intervention test }\end{array}$ \\
\hline $\begin{array}{l}\text {-I use pictures, tables, and figures } \\
\text { to increase my understanding. } \\
\text {-I use context clues to better } \\
\text { understand what I read. } \\
\text {-I skim the text first before I read, } \\
\text { to help my understanding }\end{array}$ & & \\
\hline
\end{tabular}

Figure 2. Hypothesised linkage between prediction skills and achievement in reading comprehension.

Furthermore, the dependent variable was measured as learners' performance in the post-intervention test. The framework further shows that learners' attributes, such as age, gender, school and sub-group are likely to moderate the relationship between the application of prediction skills and learners' achievement in reading comprehension. 


\section{Methodology}

The design, methods and approaches used in the study to capture, process, analyse, and interpret the data are founded on the positivist and constructivist philosophical schools, which are complementary ontologically, epistemologically and methodologically (Wong, 2014; Ashley \& Orenstein, 2005). Based on the two schools of thought, both quantitative and qualitative methods were applied to capture primary data on learners' prediction practices when reading texts and their scores in the post-intervention test, which was designated, learners' achievement in reading comprehension.

The Solomon Four-Group Design was applied to guide the research process. Based on the design's principles, eight public primary schools were randomly assigned into two groups: experimental and control. The experimental group included schools code-named G, H, I, and J, while the control group consisted of schools K, L, M, and N. Whereas teachers of English language in the experimental group were trained on how to correctly apply the interactive approach instruction, those in the control group were not. More still, learners in Schools $\mathrm{G}$ and $\mathrm{H}$ in the experimental group, and Schools $\mathrm{K}$ and $\mathrm{L}$ in the control group were subjected to a pre-intervention test. After training, teachers in the experimental group were observed for a period of three months. At the end of the observation period, learners in all the eight schools were subjected a post-intervention test. The following publications provide details about the design used in this study: Symmons (2013), and Boushey, Harris, Bruemmer, Archer, and Van Horn (2006).

The study targeted all the then 361 public primary schools in Vihiga County. Within the schools, the study targeted standard six learners and teachers of English language. Standard six was targeted because it marks the point when learners start preparing for KCPE; hence, the involvement of such learners was likely to contribute positively towards their preparation for said examinations. Both census and purposive sampling procedures were applied at various levels to obtain sample sizes indicated in Table 1, Part A. In this regard, all the five sub-counties were involved in the study based on the principles of a census. From each sub-county, two schools were purposively selected, based on their participation in KCPE for at least five years and rural-urban representation. The process yielded 12 schools, of which four participated in the pilot study, and eight involved in the main study. From each school, one teacher of English language, who instructs standard six learners, was selected purposively. Besides, 420 standard six learners were involved in the study; of which 280 were involved in the main study, and 140 participated in the pilot study.

In addition, Part B of Table 1 shows the distribution of learners and teachers by gender. Data were sourced using a questionnaire for learners, a questionnaire and an interview schedule for teachers; an observation schedule as well as a pre- and post- test tool for learners. The instruments were pilot-tested between January and April, 2017 in four schools. In total, four teachers and 140 learners were involved in the pilot study. The tools were adjusted to improve content, clarity, and feasibility, based on the issues arising.

The investigator obtained an authorization letter for data collection from the National Commission for Science, Technology and Innovation, as well as an introduction letter from the University of Nairobi to facilitate the data collection process, which occurred between May and August, 2017. Data collection started with administration of the pre-intervention test to learners in Schools G and H in the experimental group, and Schools $\mathrm{K}$ and $\mathrm{L}$ in the control group. This was followed by the training of teachers in the experimental group on how to correctly apply the interactive approach instruction; observation of comprehension reading lessons in both groups for three months. At the end of the observation period, learners in both groups were subjected to a 
post-intervention test to check whether or not, the training provided to teachers had influenced a significant change on learners' achievement in reading comprehension. The questionnaires were also administered to learners and teachers in both groups.

Table 1

Sample Sizes

\begin{tabular}{|c|c|c|c|c|c|c|}
\hline \multicolumn{7}{|l|}{ Part A } \\
\hline \multirow{2}{*}{ Level } & \multicolumn{4}{|l|}{ Sample size } & \multirow{2}{*}{\multicolumn{2}{|c|}{ Method of determination }} \\
\hline & Main study & \multicolumn{2}{|l|}{ Pilot study } & Total & & \\
\hline Sub-counties & 4 & 1 & & 5 & \multicolumn{2}{|c|}{ Census } \\
\hline Schools & 8 & 4 & & 12 & \multicolumn{2}{|c|}{ Solomon Four-Group Design } \\
\hline Teachers & 8 & 4 & & 12 & \multicolumn{2}{|c|}{ Census } \\
\hline Learners & 280 & 140 & & 420 & \multicolumn{2}{|l|}{ Census } \\
\hline \multicolumn{7}{|l|}{ Part B } \\
\hline \multirow{2}{*}{ Sub-county } & \multirow{2}{*}{ School } & \multicolumn{3}{|l|}{ Learners } & \multicolumn{2}{|c|}{ Teachers } \\
\hline & & Girls & Boys & Total & Female & Male \\
\hline Luanda & G & 19 & 16 & 35 & & 1 \\
\hline Emuhaya & $\mathrm{H}$ & 18 & 16 & 34 & 1 & \\
\hline Hamisi & I & 20 & 18 & 38 & 1 & \\
\hline Sabatia & $\mathrm{J}$ & 19 & 17 & 36 & 1 & \\
\hline Luanda & $\mathrm{K}$ & 22 & 14 & 36 & & 1 \\
\hline Emuhaya & $\mathrm{L}$ & 17 & 17 & 34 & & 1 \\
\hline Hamisi & M & 19 & 17 & 36 & 1 & \\
\hline Sabatia & $\mathrm{N}$ & 16 & 15 & 31 & 1 & \\
\hline Total & 8 & 150 & 130 & 280 & 5 & 3 \\
\hline
\end{tabular}

Quantitative analysis techniques included one-way analysis of variance, which was used to generate mean scores; independent samples $t$-tests, which determined the significance of variations between scores achieved by the two groups; cross tabulations with Chi-square tests, which determined statistical associations between learners' perceptions on various reading practices and scores obtained in the post-intervention test. Lastly, linear regression analysis was performed to determine the influence of prediction skills on learners' achievement in reading comprehension. The Statistical Package for Social Sciences (SPSS) facilitated quantitative data analysis. Furthermore, qualitative data were transcribed and subjected to thematic analysis, which identified emerging sub-themes, patterns of change in learners' achievement in reading comprehension. Detailed information about the methods applied in this study may be accessed in the following publications: Ritter (2010), Polit and Beck (2006), Best and Khan (2004), Bryman and Cramer (1998), as well as C. F. Nachmias and D. Nachmias (1996), among others.

The study complied with social research ethical principles, which entailed obtaining informed consent from parents, before involving learners in the study. In this regard, the investigator wrote brief letters to parents, explaining the study, its purpose, potential benefits and the need for voluntary participation. The letter also contained information about the right to withdraw consent of participation for their children at any time before or during data collection. Learners also filled in assent forms, confirming their willingness to participate in the study. Teachers were also guided through the consenting process. Lastly, all participants were assured about confidentiality of the information obtained from the process. 


\section{Results}

The results are clustered around four thematic sub-sections, including univariate analysis of learners' achievement in reading comprehension, bivariate analysis of learners' profile and achievement in reading comprehension, bivariate analysis of learners' perceptions on reading practices aligned to prediction skills and achievement in reading comprehension, as well as multivariate analysis of prediction skills and achievement in reading comprehension. Details are presented under the following sub-sections.

\section{Univariate Analysis of Learners' Achievement in Reading Comprehension}

The data were sourced from 279 learners, including 142 (50.9\%) in the experimental group and 137 $(49.1 \%)$ in the control group. The score obtained by each learner in the post-intervention test was designated as "learners' achievement in reading comprehension", which is the dependent variable. The analysis entailed determining the statistical significance of variation in the scores obtained by learners in the experimental group and those in the control group. This was achieved by applying the $t$-test for independent samples, with the aim of determining the statistical significance of the difference in mean scores obtained by learners in the two groups. In this regard, the results in Table 2 show that learners in the experimental group obtained a mean score of 35.59 (95\% Confidence Interval [CI] = 34.71-37.07); while those in the control group achieved a mean score of $22.32(95 \% \mathrm{CI}=21.46-23.18)$. To facilitate readability of the results in Table 2 , the symbol $n$ is the sample size, SD stands for standard deviation, SE is the standard error, Sig. means significance (also known as $p$-value) and $\mathrm{df}$ is the degree of freedom.

Table 2

Variation in Post-test Scores Between Learners in the Experimental and Control Groups

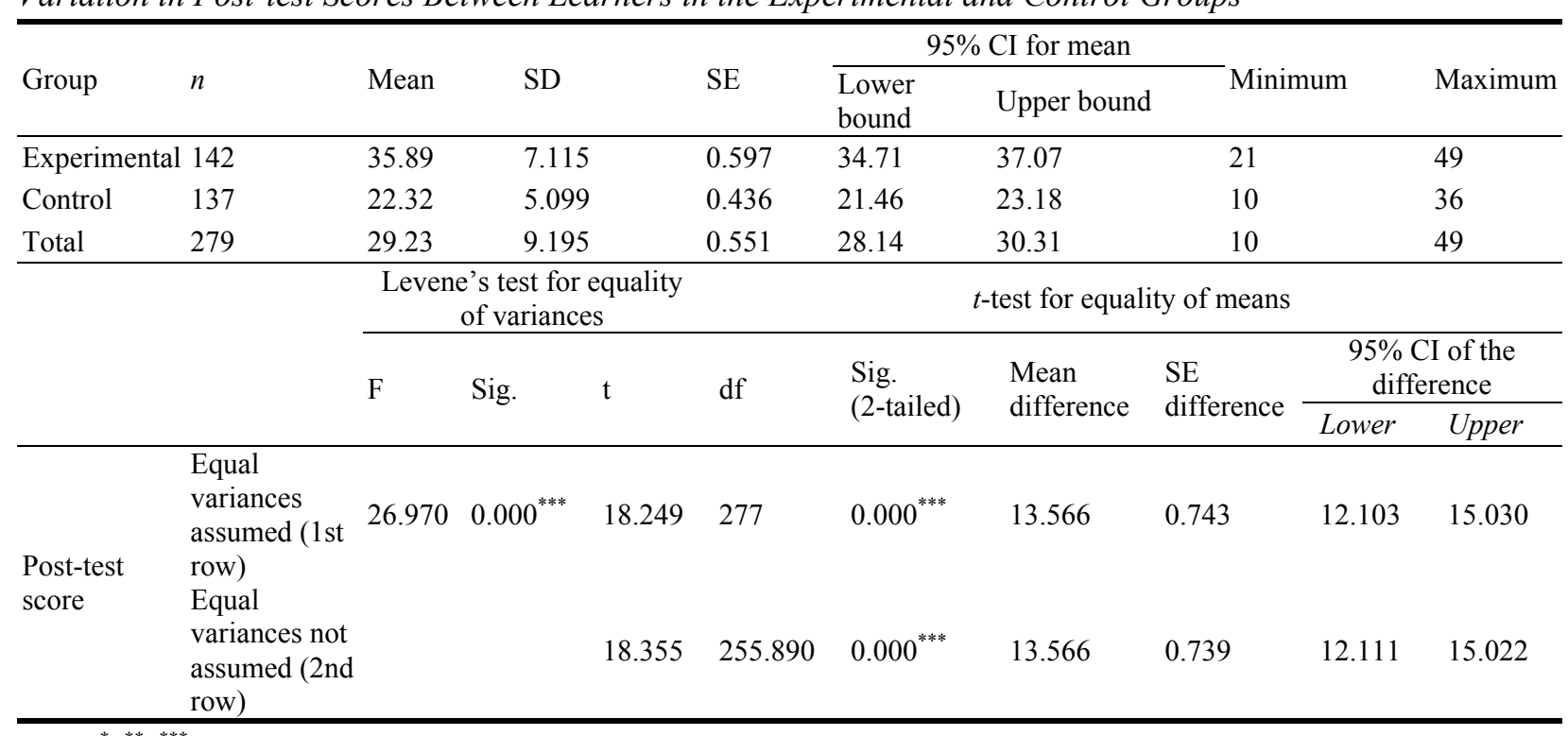

Notes. ${ }^{*},{ }^{* *},{ }^{* * *}$ show significance at $p<0.1, p<0.05$, and $p<0.01$ error margins, respectively.

One of the outputs generated by the $t$-test for independent samples is Levene's test for equality of variance, which enables analysts to determine whether variances between two groups is equal or not. Variance between any two groups is assumed to be equal if the significance value (Sig.) for Levene's test is greater than 0.05 . In such situations, results are read from the first row of Table 2. However, variances between the groups is 
assumed to be unequal when the significance of Levene's test is less than or equal to 0.05 . Under such circumstances, results are read from the second row. In addition, the difference of the mean scores between two groups or samples is indicated by the Sig. (2-tailed) column. If the value of Sig. (2-tailed) is greater than 0.05, then there is no significant difference between the means scores obtained by two groups. Contrastingly, if the value of Sig. (2-tailed) is less than or equal to 0.05 , then there is a significant difference in the mean scores obtained by the two groups.

Based on the foregoing principles, Table 2 shows that the Sig. value for Levene's test was 0.000 , which is less than 0.05 , thus, implying that equal variances between the two groups were not assumed; hence, the results are read from the second row. In this regard, the analysis obtained a $t$-statistic of 18.355 with a significance value (Sig. [2-tailed]) of 0.000 , which suggests up to $99 \%$ chance that mean scores obtained by learners in the experimental and control groups were significantly different. Given that the mean score obtained by learners in the experimental group (35.89) was higher than that of learners in the control group (22.32), the results suggest up to $99 \%$ chance that the training provided to teachers in the experimental group might have improved teachers' competence in applying the interactive approach instruction, which in turn, enhanced learners' achievement in reading comprehension.

\section{Bivariate Analysis of Learners' Profile and Achievement in Reading Comprehension}

To facilitate bivariate analyses, the measurement scale of scores obtained by learners in the post-intervention test was changed from interval to nominal, by recoding into four categories, calibrated as "< 20 marks", " $20-29$ marks", "30-39 marks", and "40+ marks". The resultant variable was cross-tabulated with learners' proximate attributes, including age, gender, school and sub-county of residence at the time of the study. The results presented in Table 3 show that slightly more than one-half of the learners, 143 (51.3\%) were aged 12, 76 (27.2\%) indicated aged 13, while $43(15.4 \%)$ were aged 14. In relation to achievement in reading comprehension, 64 (49.6\%) learners aged 12, 32 (24.8\%) aged 13, and 20 (15.5\%) aged 14 obtained 20-29 marks. Those in the 30-39 marks category were 28 (47.5\%) learners aged 12 and 21 (35.6\%) who were 13 years old. Based on this, the cross-tabulation analysis yielded a $\chi^{2}$ of $13.082(\mathrm{df}=12, p$-value $=0.023)$, which suggests up to $95 \%$ chance that learners' achievement in reading comprehension significantly associated with their age.

In terms of gender, the results in Table 3 show that learners included 130 (46.6\%) boys and $149(53.4 \%)$ girls. In relation to achievement in reading comprehension, the cross-tabulation results indicate that those who scored $<20$ marks were 20 (48.8\%) boys and 21 (51.2\%) girls, while $22(44.0 \%)$ boys and 28 (56.0\%) girls achieved 40+ marks. However, association between learners' gender and achievement in reading comprehension was not statistically significant $\left(\chi^{2}=0.477, \mathrm{df}=3, p\right.$-value $\left.=0.924\right)$. This suggests that there was no significant difference between scores obtained by boys and girls in the post-intervention test.

As indicated in Table 3, learners were drawn from eight public primary schools, coded as G, H, I, J, K, L, $\mathrm{M}$, and N. In this regard, $38(13.6 \%)$ learners were sampled from School I, followed by $36(12.9 \%)$ in Schools $\mathrm{K}$ and M, each; while 35 (12.5\%) were based in School G. The category of $<20$ marks included $15(36.6 \%)$ learners in School N, and 14 (34.1\%) in School M. Those who obtained 40+ marks were 15 (30.0\%) learners of Schools H and I, each; while 11 (22.0\%) learners were members of School G. Based on this, the analysis revealed that learners' achievement in comprehension reading significantly associated with their schools $\left(\chi^{2}=\right.$ 15.719, $\mathrm{df}=9, p$-value $=0.013$ ). This suggests that performance in the post-intervention test varied significantly across the schools. 
Table 3

Cross-tabulation Analysis of Learners' Attributes and Achievement in Reading Comprehension

\begin{tabular}{|c|c|c|c|c|c|c|c|c|c|c|c|c|c|}
\hline \multirow{3}{*}{$\begin{array}{l}\text { Learners' } \\
\text { attributes }\end{array}$} & \multicolumn{10}{|c|}{ Post-test scores } & \multirow{2}{*}{\multicolumn{3}{|c|}{ Test results }} \\
\hline & \multicolumn{2}{|c|}{$<20$} & \multicolumn{2}{|c|}{$20-29$} & \multicolumn{2}{|c|}{$30-39$} & \multicolumn{2}{|c|}{$40+$} & \multicolumn{2}{|c|}{ Total } & & & \\
\hline & Freq & $\%$ & Freq & $\%$ & Freq & $\%$ & Freq & $\%$ & Freq & $\%$ & $\chi^{2}$ & $\mathrm{df}$ & Sig. \\
\hline \multicolumn{14}{|l|}{ Age } \\
\hline 11 years & 1 & 2.4 & 5 & 3.9 & 0 & 0.0 & 0 & 0.0 & 6 & 2.2 & & & \\
\hline 12 years & 22 & 53.7 & 64 & 49.6 & 28 & 47.5 & 29 & 58.0 & 143 & 51.3 & & & \\
\hline 13 years & 11 & 26.8 & 32 & 24.8 & 21 & 35.6 & 12 & 24.0 & 76 & 27.2 & 13.082 & 12 & $0.023^{* *}$ \\
\hline 14 years & 7 & 17.1 & 20 & 15.5 & 7 & 11.9 & 9 & 18.0 & 43 & 15.4 & & & \\
\hline 15 years & 0 & 0.0 & 8 & 6.2 & 3 & 5.1 & 0 & 0.0 & 11 & 3.9 & & & \\
\hline Total & 41 & 100.0 & 129 & 100.0 & 59 & 100.0 & 50 & 100.0 & 279 & 100.0 & & & \\
\hline \multicolumn{14}{|l|}{ Gender } \\
\hline Male & 20 & 48.8 & 62 & 48.1 & 26 & 44.1 & 22 & 44.0 & 130 & 46.6 & & & \\
\hline Female & 21 & 51.2 & 67 & 51.9 & 33 & 55.9 & 28 & 56.0 & 149 & 53.4 & 0.477 & 3 & 0.924 \\
\hline Total & 41 & 100.0 & 129 & 100.0 & 59 & 100.0 & 50 & 100.0 & 279 & 100.0 & & & \\
\hline \multicolumn{14}{|l|}{ School } \\
\hline $\mathrm{G}$ & 0 & 0.0 & 13 & 10.1 & 11 & 18.6 & 11 & 22.0 & 35 & 12.5 & & & \\
\hline $\mathrm{H}$ & 0 & 0.0 & 7 & 5.4 & 12 & 20.3 & 15 & 30.0 & 34 & 12.2 & & & \\
\hline I & 0 & 0.0 & 14 & 10.9 & 9 & 15.3 & 15 & 30.0 & 38 & 13.6 & & & \\
\hline $\mathrm{J}$ & 0 & 0.0 & 10 & 7.8 & 16 & 27.1 & 9 & 18.0 & 35 & 12.5 & 15.719 & 9 & $0.013^{* *}$ \\
\hline $\mathrm{K}$ & 8 & 19.5 & 19 & 14.7 & 9 & 15.3 & 0 & 0.0 & 36 & 12.9 & & & \\
\hline $\mathrm{L}$ & 4 & 9.8 & 28 & 21.7 & 2 & 3.4 & 0 & 0.0 & 34 & 12.2 & & & \\
\hline M & 14 & 34.1 & 22 & 17.1 & 0 & 0.0 & 0 & 0.0 & 36 & 12.9 & & & \\
\hline $\mathrm{N}$ & 15 & 36.6 & 16 & 12.4 & 0 & 0.0 & 0 & 0.0 & 31 & 11.1 & & & \\
\hline Total & 41 & 100.0 & 129 & 100.0 & 59 & 100.0 & 50 & 100.0 & 279 & 100.0 & & & \\
\hline \multicolumn{14}{|c|}{ Sub-county } \\
\hline Luanda & 8 & 19.5 & 32 & 24.8 & 20 & 33.9 & 11 & 22.0 & 71 & 25.4 & & & \\
\hline Emuhaya & 4 & 9.8 & 35 & 27.1 & 14 & 23.7 & 15 & 30.0 & 68 & 24.4 & & & \\
\hline Hamisi & 14 & 34.1 & 36 & 27.9 & 9 & 15.3 & 15 & 30.0 & 74 & 26.5 & 166.542 & 21 & $0.000^{* * *}$ \\
\hline Sabatia & 15 & 36.6 & 26 & 20.2 & 16 & 27.1 & 9 & 18.0 & 66 & 23.7 & & & \\
\hline Total & 41 & 100.0 & 129 & 100.0 & 59 & 100.0 & 50 & 100.0 & 279 & 100.0 & & & \\
\hline
\end{tabular}

The results in Table 3 further show that 74 (26.5\%) learners were drawn from Hamisi Sub-County, 71 (25.4\%) were sampled from Luanda, 68 (24.4\%) were natives of Emuhaya, while 66 (23.7\%) schooled in Sabatia. In relation to achievement in reading comprehension, those who scored 20-29 marks included 36 (27.9\%) learners in Hamisi, 35 (27.1\%) in Emuhaya and 32 (24.8\%) in Luanda. Besides, 15 (30.0\%) learners in Hamisi and Emuhaya Sub-Counties, each; as well as 11 (22.0\%) learners in Luanda scored 40+ marks. Based on this, the analysis revealed that learners' achievement in reading comprehension and the sub-counties of residence were significantly associated $\left(\chi^{2}=166.542, \mathrm{df}=21, p\right.$-value $\left.=0.000\right)$. This suggests that achievement in reading comprehension varied significantly across the sub-counties.

\section{Bivariate Analysis of Prediction Skills \& Learners' Achievement in Reading Comprehension}

Prediction skills was measured using five perception statements aligned to pertinent reading practices. In this regard, learners were requested to indicate their views regarding each perception statement on a five-point measurement scale, calibrated as "strongly agree", "agree", "undecided", "disagree", and "strongly disagree". 
The views were then cross-tabulated against achievement in reading comprehension; and the results presented in the following sub-section.

The first perception statement asserted that "I try to visualise information to help me remember what I read". The results which are summarised in Table 4 show that of the 279 learners, 107 (38.4\%) agreed with the assertion, while 29 (10.4\%) agreed strongly. Contrastingly, 73 (26.2\%) learners voiced disagreement with the statement, while $60(21.5 \%)$ disagreed strongly. Cumulatively, the results further show that up to $136(48.7 \%)$ learners affirmed the statement; thereby, suggesting that "visualisation of information to facilitate recollection of passage contents" was practiced by nearly one-half of the learners. Those who felt that the statement was untrue were $60(21.5 \%)$.

The cross-tabulation results in Table 4 further show that among the 41 learners who scored $<20$ marks, 24 $(58.5 \%)$ hinted that the statement was untrue regarding their reading practices, while $15(36.6 \%)$ indicated that it was true. In the category of $40+$ marks $(n=50), 38(76.0 \%)$ learners said the statement was correct; while 10 $(20.0 \%)$ confuted it. More still, the category of 20-29 marks $(n=129)$ consisted of $71(55.0 \%)$ learners who felt the statement was untrue about their reading practices and $53(41.1 \%)$ who upheld it. Consequently, the analysis revealed that learners' achievement in reading comprehension significantly associated with the practice of "visualising information to facilitate recollection of text contents" at $95 \%$ confidence level $\left(\chi^{2}=25.649\right.$, $\mathrm{df}=$ $12, p$-value $=0.012$ )

Learners also provided their views regarding the second perception statement, which claimed that "I guess what the material is all about when I read the information". The results presented in Table 4 show that of the 279 learners, $120(43.0 \%)$ agreed with the statement, while $65(23.3 \%)$ agreed strongly. Those who disagreed with it were $46(16.5 \%)$ learners, while 37 (13.3\%) expressed strong disagreement. Cumulative results indicate that whereas $185(66.3 \%)$ learners believed that the statement truly reflected their reading practices, about one-third, 83 (29.7\%) refuted it on account of being untrue.

More still, the cross-tabulation results show that among the learners who scored $<20$ marks $(n=41), 21$ $(51.2 \%)$ affirmed the statement, while $18(43.9 \%)$ hinted that the statement was untrue. Contrastingly, the category of $40+$ marks $(n=50)$, included $38(76.0 \%)$ learners who felt that the statement correctly portrayed their reading practices; while $10(20.0 \%)$ clued that it was incorrect. The category of 30-39 marks $(n=59)$ consisted of $45(76.3 \%)$ learners who endorsed the statement and 11 (18.6\%) who said it was untrue. Following the cross-tabulations, the analysis proved that learners' achievement in reading comprehension significantly associated with the practice of "guessing the content of materials when reading" at $90 \%$ confidence level $\left(\chi^{2}=\right.$ 19.492, $\mathrm{df}=12, p$-value $=0.077$ ).

The third perception statement averred that "I use pictures, tables and figures to increase my understanding”. In this regard, Table 4 shows that whereas 117 (41.9\%) learners agreed with the statement, 74 (26.5\%) agreed strongly. However, 40 (14.3\%) learners disagreed with it, while 39 (14.0\%) disagreed strongly. Cumulative results further show that of the 279 learners, 191 (68.5\%) endorsed the statement; thereby, suggesting that the "use of pictures, tables and figures to increase the understanding of texts" was a common practice among the learners. Those who countered it for being untrue were $79(28.3 \%)$ learners.

Table 4 further shows that in the category of $<20$ marks $(n=41)$, nearly two-thirds, $24(58.5 \%)$ learners, felt that the statement was consistent with their reading practices; while $14(34.1 \%)$ said that the statement was inconsistent. In the category of 40+ marks $(n=50), 41(82.0 \%)$ learners affirmed the statement, while eight $(16.0 \%)$ rebutted it for being untrue. Among those who scored 20-29 marks $(n=129), 82(63.6 \%)$ learners said 
the statement was correct, while $45(34.9 \%)$ refuted it. Based on the cross-tabulation results, the analysis obtained a $\chi^{2}$ of 22.921 , with 12 degrees of freedom and a $p$-value of 0.028 , which suggests up to $95 \%$ chance that learners' achievement in reading comprehension significantly associated with the "use of pictures, tables and figures to increase understanding of texts".

Table 4

Aspects of Prediction Skills and Achievement in Reading Comprehension

\begin{tabular}{|c|c|c|c|c|c|c|c|c|c|c|}
\hline \multirow{3}{*}{ Aspects of prediction skills } & \multicolumn{10}{|c|}{ Post-test scores } \\
\hline & \multicolumn{2}{|c|}{$<20$} & \multicolumn{2}{|c|}{$20-29$} & \multicolumn{2}{|c|}{$30-39$} & \multicolumn{2}{|c|}{$40+$} & \multicolumn{2}{|c|}{ Total } \\
\hline & \multicolumn{2}{|c|}{ Freq $\%$} & \multicolumn{2}{|c|}{ Freq $\%$} & \multicolumn{2}{|c|}{ Freq $\%$} & \multicolumn{2}{|c|}{ Freq $\%$} & \multicolumn{2}{|c|}{ Freq $\%$} \\
\hline \multicolumn{11}{|c|}{ I try to visualize information to help me remember what I read. } \\
\hline Strongly agree & 5 & 12.2 & 10 & 7.8 & 7 & 11.9 & 7 & 14.0 & 29 & 10.4 \\
\hline Agree & 10 & 24.4 & 43 & 33.3 & 23 & 39.0 & 31 & 62.0 & 107 & 38.4 \\
\hline Undecided & 2 & 4.9 & 5 & 3.9 & 1 & 1.7 & 2 & 4.0 & 10 & 3.6 \\
\hline Disagree & 16 & 39.0 & 36 & 27.9 & 16 & 27.1 & 5 & 10.0 & 73 & 26.2 \\
\hline Strongly disagree & 8 & 19.5 & 35 & 27.1 & 12 & 20.3 & 5 & 10.0 & 60 & 21.5 \\
\hline Total & 41 & 100.0 & 129 & 100.0 & 59 & 100.0 & 50 & 100.0 & 279 & 100.0 \\
\hline \multicolumn{11}{|c|}{ I try to guess what the material is all about when I read the information. } \\
\hline Strongly agree & 8 & 19.5 & 34 & 26.4 & 14 & 23.7 & 9 & 18.0 & 65 & 23.3 \\
\hline Agree & 13 & 31.7 & 47 & 36.4 & 31 & 52.5 & 29 & 58.0 & 120 & 43.0 \\
\hline Undecided & 2 & 4.9 & 4 & 3.1 & 3 & 5.1 & 2 & 4.0 & 11 & 3.9 \\
\hline Disagree & 13 & 31.7 & 23 & 17.8 & 5 & 8.5 & 5 & 10.0 & 46 & 16.5 \\
\hline Strongly disagree & 5 & 12.2 & 21 & 16.3 & 6 & 10.2 & 5 & 10.0 & 37 & 13.3 \\
\hline Total & 41 & 100.0 & 129 & 100.0 & 59 & 100.0 & 50 & 100.0 & 279 & 100.0 \\
\hline \multicolumn{11}{|c|}{ I use pictures, tables and figures to increase my understanding. } \\
\hline Strongly agree & 6 & 14.6 & 38 & 29.5 & 12 & 20.3 & 18 & 36.0 & 74 & 26.5 \\
\hline Agree & 18 & 43.9 & 44 & 34.1 & 32 & 54.2 & 23 & 46.0 & 117 & 41.9 \\
\hline Undecided & 3 & 7.3 & 2 & 1.6 & 3 & 5.1 & 1 & 2.0 & 9 & 3.2 \\
\hline Disagree & 5 & 12.2 & 26 & 20.2 & 6 & 10.2 & 3 & 6.0 & 40 & 14.3 \\
\hline Strongly disagree & 9 & 22.0 & 19 & 14.7 & 6 & 10.2 & 5 & 10.0 & 39 & 14.0 \\
\hline Total & 41 & 100.0 & 129 & 100.0 & 59 & 100.0 & 50 & 100.0 & 279 & 100.0 \\
\hline \multicolumn{11}{|c|}{ I use context clues to better understand what I read. } \\
\hline Strongly agree & 1 & 2.4 & 10 & 7.8 & 7 & 11.9 & 7 & 14.0 & 25 & 9.0 \\
\hline Agree & 17 & 41.5 & 39 & 30.2 & 27 & 45.8 & 20 & 40.0 & 103 & 36.9 \\
\hline Undecided & 8 & 19.5 & 14 & 10.9 & 6 & 10.2 & 8 & 16.0 & 36 & 12.9 \\
\hline Disagree & 11 & 26.8 & 45 & 34.9 & 14 & 23.7 & 14 & 28.0 & 84 & 30.1 \\
\hline Strongly disagree & 4 & 9.8 & 21 & 16.3 & 5 & 8.5 & 1 & 2.0 & 31 & 11.1 \\
\hline Total & 41 & 100.0 & 129 & 100.0 & 59 & 100.0 & 50 & 100.0 & 279 & 100.0 \\
\hline \multicolumn{11}{|c|}{ I skim the text first before I read, to help my understanding. } \\
\hline Strongly agree & 9 & 22.0 & 33 & 25.6 & 18 & 30.5 & 12 & 24.0 & 72 & 25.8 \\
\hline Agree & 13 & 31.7 & 43 & 33.3 & 21 & 35.6 & 30 & 60.0 & 107 & 38.4 \\
\hline Undecided & 4 & 9.8 & 4 & 3.1 & 3 & 5.1 & 3 & 6.0 & 14 & 5.0 \\
\hline Disagree & 9 & 22.0 & 36 & 27.9 & 12 & 20.3 & 3 & 6.0 & 60 & 21.5 \\
\hline Strongly disagree & 6 & 14.6 & 13 & 10.1 & 5 & 8.5 & 2 & 4.0 & 26 & 9.3 \\
\hline Total & 41 & 100.0 & 129 & 100.0 & 59 & 100.0 & 50 & 100.0 & 279 & 100.0 \\
\hline
\end{tabular}

The fourth perception statement asserted that "I use context clues to better understand what I read". In this regard, the results in Table 4 indicate that of the 279 learners, 103 (36.9\%) agreed with the statement, while 25 
(9.0\%) agreed strongly. However, 84 (30.1\%) learners disagreed with it, while 31 (11.1\%) disagreed strongly. In addition, cumulative results indicate that $128(45.9 \%)$ learners affirmed the statement; meaning that they "use context clues to better understand what they read". Contrastingly, up to 115 (41.2\%) learners were non-users of context clues in their reading. In relation to achievement in reading comprehension, the results in Table 4 show that in the category of $<20$ marks $(n=41), 18(43.9 \%)$ backed the statement for being true; while $15(36.6 \%)$ disproved it. Among those who scored 40+ marks $(n=50), 27(54.0 \%)$ learners upheld the statement, while $15(30.0 \%)$ countered it for being untrue. In the 30-39 marks $(n=59)$ category, $34(57.6 \%)$ learners avowed that the statement was correct, while 19 (32.2\%) refuted it. Consequently, the analysis revealed that learners' achievement in reading comprehension significantly associated with the practice of using context clues to better understand what they read, at $90 \%$ confidence level $\left(\chi^{2}=19.088, \mathrm{df}=12\right.$, $p$-value $=0.086$ ).

Learners also expressed their thoughts regarding the fifth perception statement, which postulated that "I skim the text first before I read to help my understanding". In this regard, Table 4 shows that those who agreed with the statement were 107 (38.4\%), and those who agreed strongly were 72 (25.8\%) learners. However, 60 (21.5\%) learners disagreed with the statement, while $26(9.3 \%)$ disagreed strongly. Cumulatively, the analysis show that of the 279 learners, $179(64.2 \%)$ acknowledged "skimming texts before reading for better understanding", while $86(30.8 \%)$ learners refuted it. The cross-tabulation results further show that of the 41 learners who obtained $<20$ marks, $22(53.7 \%)$ affirmed the statement; while $15(36.6 \%)$ countered it. The 40+ marks category $(n=50)$, consisted of $42(84.0 \%)$ learners who averred the statement, and another five $(10.0 \%)$ who felt it was incorrect. Among those who scored 30-39 marks $(n=59), 39(66.1 \%)$ learners upheld the statement, while 17 (28.8\%) refuted it. Based on this, the study demonstrated that learners' achievement in reading comprehension significantly associated with the practice of "skimming texts before reading to facilitate understanding", at 95\% confidence level $\left(\chi^{2}=22.204, \mathrm{df}=12, p\right.$-value $\left.=0.035\right)$.

The five reading practices analysed in Table 4 were aggregated to generate optimal estimates regarding the consistency with which learners applied prediction skills when reading comprehension passages. The output, which was measured using five ordinal categories, marked as, "very consistent", "consistent", "undecided", "inconsistent", and "very inconsistent", was cross-tabulated with learners' group. The process aimed at determining variation between learners in the experimental group and those in the control group concerning consistency in using prediction skills when reading comprehension passages. In this regard, Figure 3 shows that of the 279 learners, 108 (38.7\%) were consistent in applying prediction skills in their reading, while $27(9.7 \%)$ were very consistent. Contrastingly, 73 (26.2\%) learners were inconsistent in deploying prediction skills when reading comprehension passages, while $16(5.7 \%)$ were very inconsistent in doing so.

The results further show those consistent in applying prediction skills when reading comprehension passages included $61(43.0 \%)$ learners in the experimental group against $47(34.3 \%)$ in the control group. Besides, 18 (12.7\%) learners in the experimental group against nine $(6.6 \%)$ in the control group were very consistent in applying the technique when reading. However, $45(32.8 \%)$ learners in the control group and 28 (19.7\%) in the experimental group were inconsistent users of such skills; while eight (5.8\%) learners in the control group against another eight $(5.6 \%)$ in the experimental group were very inconsistent in doing so.

Cumulatively, 79 (55.7\%) learners in the experimental group against 56 (40.9\%) in the control group were consistent in applying prediction skills when reading comprehension passages; however, 53 (38.7\%) learners in the control group compared to $36(25.3 \%)$ in the experimental group were inconsistent users. In this regard, the 
analysis revealed that variation between learners in the experimental group and those in the control group regarding the consistency of applying prediction skills when reading comprehension passages was significant at $90 \%$ confidence level $\left(\chi^{2}=8.705, \mathrm{df}=4, p\right.$-value $\left.=0.069\right)$. This suggests that more learners in the experimental group than in the control group were consistent in using prediction skills when reading comprehension passages.

\section{$\llbracket$ Experimental $(n=142) \quad \square$ Control $(n=137) \square$ Total $(n=279)$}

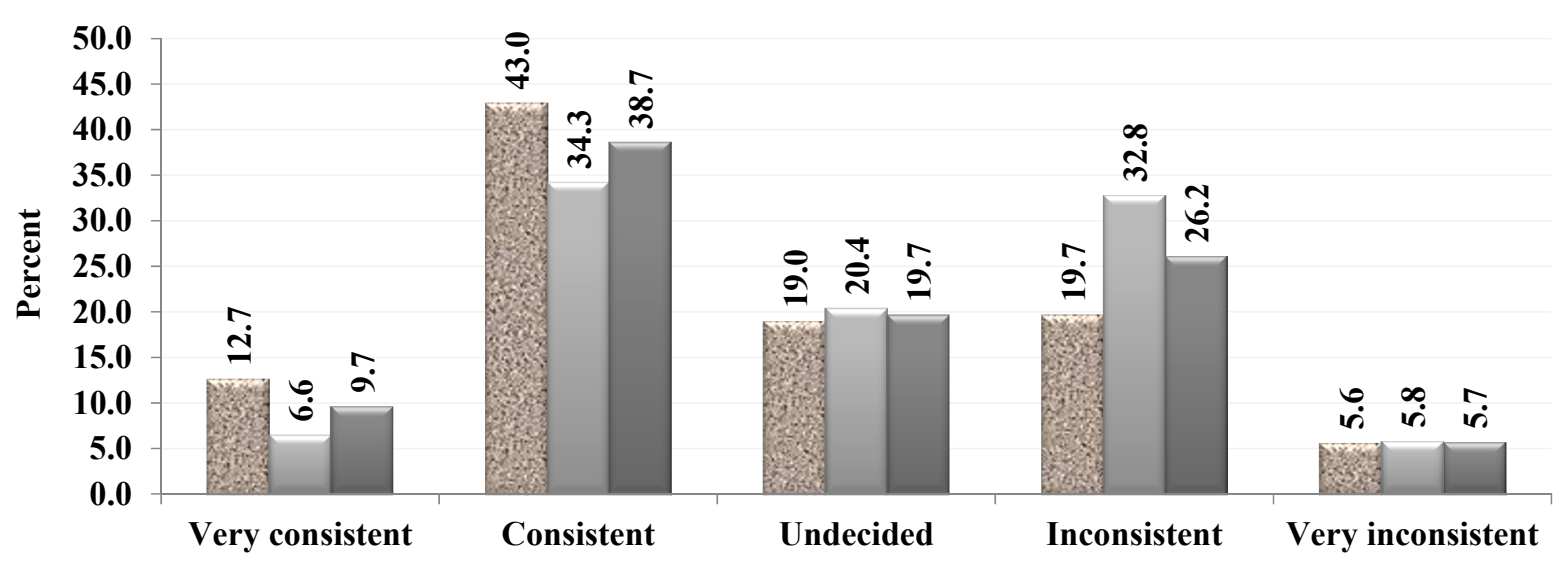

Learners' aggregated views

Figure 3. Learners' aggregated perceptions on the application of prediction skills when reading.

\section{Multivariate Analysis of Prediction Skills \& Learners' Achievement in Comprehension Reading}

The study focused on determining how learners' use of prediction skills influences their achievement in reading comprehension. In this regard, application of prediction skills were set as the independent variable, while learners' achievement in reading comprehension was designated the dependent variable. Both variables were incorporated in the regression analysis. Learners' proximate attributes were included in the regression process to moderate the influence of prediction skills on learners' achievement in reading comprehension. The analysis generated two regression models - one for the experimental group and one for the control group.

The results presented in Table 5 show that the influence of prediction skills on learners' achievement in reading comprehension was positive in both models (Model 1: Beta $=0.358, t=1.302$; Model 2: Beta $=0.278$, $t=0.357$ ). Again, in both models, learners' prediction skills caused a proportionate increase in learners' achievement in reading comprehension. However, the influence of prediction skills seemed to be stronger in the experimental group than in the control group; which in turn, suggests that learners instructed by trained teachers applied prediction skills more often, which in turn, improved their achievement in reading comprehension. It logically follows that trained teachers in the experimental group were more effective in developing learners' prediction skills than their colleagues in control schools. However, the results show that whereas in Model 1 the variable's influence was significant at 90\% confidence level $(p=0.077)$; in Model 2, the variable's influence was not significant $(p=0.285)$.

This further suggests that application of prediction skills caused a significant influence on learners' achievement in reading comprehension in the experimental group; while in the control group, the influence was 
not significant. Again this reaffirms that trained teachers were better in encouraging application of prediction skills among learners. Based on the results, the null hypothesis $\left(\mathrm{H}_{0}\right)$, which stated that "prediction skills have no significant influence on standard six learners' achievement in reading comprehension", was rejected in Model 1 for being untrue. However, the hypothesis was not rejected in Model 2 for insufficient of empirical evidence to warrant such action.

Table 5

Influence of Prediction Skills on Learners' Achievement in Reading Comprehension

\begin{tabular}{|c|c|c|c|c|c|c|}
\hline \multirow{2}{*}{\multicolumn{2}{|c|}{ Models }} & \multicolumn{2}{|c|}{ Unstandardized coefficients } & \multirow{2}{*}{$\begin{array}{l}\text { Standardised coefficients } \\
\text { B }\end{array}$} & \multirow{2}{*}{$-\mathrm{T}$} & \multirow{2}{*}{ Sig. } \\
\hline & & $\mathrm{B}$ & Std. error & & & \\
\hline \multirow{6}{*}{1} & (Constant) & 32.351 & 2.745 & & 5.631 & $0.000^{* * *}$ \\
\hline & Prediction skills & 0.465 & 0.222 & 0.358 & 1.302 & $0.077^{*}$ \\
\hline & Age & 0.364 & 0.682 & 0.045 & 0.533 & 0.595 \\
\hline & Gender ${ }^{\dagger}$ & -0.002 & 1.200 & -0.000 & -0.002 & 0.999 \\
\hline & $\operatorname{School}^{\dagger}$ & -1.496 & 1.198 & -0.235 & -1.249 & 0.214 \\
\hline & Sub-group $^{+}$ & 4.346 & 2.665 & 0.306 & 1.631 & 0.105 \\
\hline \multirow{6}{*}{2} & (Constant) & 26.574 & 2.732 & & 4.095 & $0.000^{* * *}$ \\
\hline & Prediction skills & 0.283 & 0.138 & 0.278 & 0.357 & 0.285 \\
\hline & Age & 0.325 & 0.405 & 0.059 & 0.801 & 0.425 \\
\hline & Gender $^{\dagger}$ & -0.053 & 0.747 & -0.005 & -0.071 & 0.944 \\
\hline & $\mathrm{School}^{\dagger}$ & -1.350 & 0.740 & -0.294 & -1.825 & 0.070 \\
\hline & Sub-group $^{+}$ & 2.770 & 1.639 & 0.273 & 1.691 & $0.067^{*}$ \\
\hline
\end{tabular}

Notes. ${ }^{* * * * * * *}$ show significance at $p<0.1, p<0.05$, and $p<0.01$ error margins, respectively; ${ }^{\dagger}$ converted into a dummy variable before inclusion into the linear regression analysis.

The results in Table 5 echo with those obtained through analysis of qualitative data. More specifically, the analysis of the qualitative data revealed a feeble relationship between learners' application of prediction skills and their achievement in reading comprehension. More specifically, application "prediction skills" was more common in the experimental group than in the control group. The study further revealed the strategies commonly used by teachers to activate learners' prediction skills, including pictures, titles, section-heads and visualisation; in this regard, teachers in both groups over-relied on pictures to stimulate learners' prediction of comprehension passage contents. Besides, most teachers use pictures contained in textbooks, with minimal effort to source additional relevant materials in the form of drawings, diagrams on chalkboards, or photographs. The main constraining factor according to participants was inadequacy of time to seek and prepare supplementary pictures for use during reading lessons, due to heavy workload, low motivation and negative school culture.

Pictures were particularly found to be useful in stimulating prediction skills among learners struggling with reading. In this regard, a participant pointed out that

I like using pictures in the textbook because even the struggling readers who never answer questions in class get an opportunity to speak. You see, all they need to do is to say what they can see in the pictures. So the pictures offer support to my struggling readers because they get a chance to answer at least a correct question during reading lessons.

The study also found that teachers in both groups used titles to develop learners' prediction skills. However, application of the strategy by both teachers and learners was found to be more common in the 
experimental than in the control group, with the variation attributed to the training provided to teachers in the experimental group. Even though all comprehension passages in textbooks have bolded titles, some teachers ignored discussing such titles with learners as a pre-reading activity for stimulating prediction of the subjects to be read. Failure to apply the strategy denied learners the opportunity to connect their prior knowledge with the subjects to be read, which constrained the understanding of comprehension passages.

More still, the application of section headings to inspire learners' prediction skills was minimal in the experimental group and rare in the control group. Section headings enable learners to focus on the content of various sections, identifying main messages and predicting contents of subsequent sections. This implies that learners not trained to pause at section headings are likely to experience difficulties remembering key messages conveyed by lengthy comprehension passages.

The application of visualisation to activate learners' prediction skills was uncommon in both groups. In this study, the analysis identified lack of training on visualisation as the key factor preventing teachers from using the strategy. In this regard, a participant stated that,

To be sincere madam, I have never heard of this skill before, and as much as I remember, I was not taught this skill at the TTC. You know most of the methods we apply in the field here, can be traced way back to our training. I can't recall learning such a skill.

These findings suggest that most teachers in both groups stifled learners' achievement in reading comprehension by depending on prior knowledge acquired from their professional training, and by not trying out alternative innovative approaches. The redundant use of traditional strategies to activate learners' prediction skills suggests that most teachers lack access to continuous professional development on interactive instructional methods.

\section{Summary and Conclusions}

This study was intended to determine the causal relationship between prediction skills and learners' achievement in reading comprehension. It was expected to generate information that would influence policy and programming decisions intended to improve the competence of English language teachers on how to apply the interactive approach instruction in comprehension reading lessons. Information generated by the study was further expected to motivate further research aimed at deepening and broadening knowledge on the interactive approach instruction vis-à-vis learners' achievement in reading comprehension, not only in Kenya, but also in other developing countries.

The findings show that application of prediction skills improved learners' achievement in reading comprehension in both groups; with the influence being stronger in the experimental than in the control group, as indicated by Beta and $t$-statistic values (Model 1: Beta $=0.358, t=1.302$; Model 2: Beta $=0.278, t=0.357$ ). Besides, the variable's influence was statistically significant in the experimental group at $90 \%$ confidence level $(p=0.077)$, but insignificant in the control group $(p=0.285)$. The findings suggest that learners instructed by trained teachers applied prediction skills more and achieved higher scores in the post-intervention test. It logically follows that trained teachers were more effective in developing learners' prediction skills than their untrained colleagues in the control group. In view of this, the null hypothesis $\left(\mathrm{H}_{0}\right)$, postulating that "prediction skills have no significant influence on standard six learners' achievement in reading comprehension", was rejected in Model 1 for being untrue. However, in Model 2, the null hypothesis was not rejected due to insufficient empirical evidence to warrant such action. 
Regarding the four strategies used by teachers and learners to activate prediction skills, pictures were most commonly applied in both groups. Notably though, most teachers relied on pictures contained in textbooks, with minimal effort to source additional relevant materials in the form of drawings, diagrams or photographs. Time constraint due to heavy workload emerged the primary factor preventing teachers from developing supplementary pictures in various forms for use during reading lessons. Other constraints included low motivation, negative school culture and inadequate awareness among teachers regarding the need for innovative approaches in developing learners' prediction skills.

The use of titles to activate learners' prediction skills was below average in both groups, but more common in the experimental group than in the control group; while the use of section headings to inspire learners' prediction skills was minimal in the experimental group, but rare in the control group. The application of visualisation was uncommon in both groups. Lack of continuous professional development on interactive instructional methods emerged the key factor preventing the optimal use of titles, section headings, and visualisation. Lack of training confined most teachers to conventional teaching resources such as pictures contained in textbooks, while constraining innovation. Lack of training also constrained the application of visualisation in comprehension reading, as teachers' training curriculum did not cover such.

The influence of prediction skills on learners' achievement in reading comprehension was statistically significant in the experimental group, but insignificant in the control group. This logically implies that teachers who accessed training on how to correctly apply the interactive approach instruction were more effective in developing learners' prediction skills than their colleagues who did not access such training. Nonetheless, the influence of prediction skills on learners' achievement in reading comprehension appears to be relatively weaker than the influence of other aspects of the interactive approach instruction, such as background knowledge, learner-generated skills and summarisation skills. This implies that learners' prediction skills were not fully developed, which in turn, amplifies the need for teachers in both groups to access training on how to apply the interactive approach instruction to activate learners' prediction skills.

Teachers' over-reliance on pictures contained in textbooks, implies that supplementary relevant resource materials such as drawings, diagrams on chalkboards and photographs were either under-used or not used at all to support development of learners' prediction skills. Even though textbooks are the most common instructional resources in classrooms, over-dependence on them prevents learners from deepening their knowledge on various subjects covered by comprehension passages. Over-dependence on textbooks also narrows opportunities for innovation and critical thinking. The situation worsens where textbooks fail to cover particular subjects sufficiently or where such books are outdated. As pointed out by Brown (2001), textbooks are often imperfect; hence, where teachers completely rely on them, the activation of learners' prediction skills may be hampered.

In their study, Makokha and Wanyonyi (2015) attributed overreliance on textbook pictures to inadequate awareness regarding the need for innovation in developing learners' prediction skills. This amplifies the need to sensitise teachers to use textbooks cautiously, while supplementing with relevant and appropriate resource materials. Addressing this challenge also requires stakeholders to sensitise teachers about innovation of supplementary resource materials that best fit learners' social and environmental contexts. An effective teacher of English is one who creates and applies diverse resource materials to develop learners' prediction skills. However, this requires relevant stakeholders, including the employer and school administrations to offer 
necessary support such as addressing staffing challenges, to enable teachers have time for innovating supplementary resource materials.

Pausing and discussing section titles is vital for learners to internalise information read for better understanding of texts. This implies that learners who fail to pause at section heading to digest contents are less likely to remember key messages conveyed by lengthy passages. Such learners may also find difficulty connecting existing knowledge with subsequent contents to be covered. Hibbing and Rankin-Erickson (2003) cautioned that reading comprehension passages can be difficult for learners if teachers ignore discussing titles during the pre-reading phase, which in turn, is likely to affect achievement in reading comprehension Consequently, teachers should be sensitised on the need to guide learners through titles to enable them connect what they know about the subject at hand with what they expect to read about in passages.

The underutilisation of section headings and visualisations in comprehension reading lessons denied learners the opportunity to develop their prediction skills fully; thereby, undermining the level of achievement in the post-intervention test. Lubliner (2005) confirmed the importance of section headings by asserting that that learners taught to understand the strategy become strategic content-area readers, who use contents of a particular section to predict information to be read in subsequent sections. The marginal application of section headings by teachers and the non-use of visualisation were attributed to lack of awareness, knowledge and requisite skills. The findings of this study suggest that teacher training curriculum does not cover some aspects of the interactive approach instruction, such as visualisation. Consequently, the study irradiates the need to update the teacher training curriculum by integrating inter alia; new instructional methods based on information and communication technology (ICT), as well as entrenching innovation to enable teachers diversify instructional resources. It is important to note that the skills acquired by teachers from professional training eventually become out-dated, particularly due to technological advancements in the teaching profession, in addition to other changes in the job market.

This advances the need for continuous professional development (CPD) through coaching, mentorship, refresher courses, workshops and conferences. Hébert (2017) confirmed this point by amplifying the need for teachers to keep abreast with new teaching methods by attending refresher courses, workshops and conferences, which is likely to sustain their effectiveness in delivering relevant content using appropriate instructional methods. Nonetheless, access to CPD remains a challenge to many teachers in most developing particularly due to funding constraints. In view of this, the need for innovative approaches for updating teachers' professional skills cannot be over-emphasised. Teacher collaboration is an initiative that establishes forums for teachers to share experiences, skills, challenges and solutions; as well as build a culture of solidarity. Burns and Lawrie (2015) reported a significant correlation between collaboration and teachers' effectiveness in applying interactive approach instructional methods, as well as teachers' willingness to adopt new innovations.

\section{References}

Akbar, S. N., \& Majid, V. (2011). The role of educational psychology in teacher education programs. Social and Behavioural Sciences, 30(3), 327-330.

Amartha, S. (2013). The influence of using interactive approach on comprehension reading ability of the tenth grade students of SMK N 5 Yogyakarta in the academic year of 2011/2012 (A thesis, Department of English Education, State University of Yogyakarta).

Anyiendah, M. S., \& Odundo, P. A. (2017). Task-based learning in value creating education: A case study of secondary schools in Vihiga Sub-county, Kenya: With focus on cooperation, tolerance, justice and citizenship. International Journal for Human and Social Studies, 5(6), 241-249. 
Ashley, D., \& Orenstein, D. M. (2005). Sociological theory: Classical statements (6th ed.). Boston, MA, USA: Pearson Education.

Best, J. W., \& Khan, J. V. (2004). Research in education (7th ed.). New Delhi: Prentice Hall of India.

Boughey, C. (2009). South Africa: University students can't read? University World News. Retrieved on 23/4/19 from http://www.universityworldnews.com/article.php?story

Boushey, C., Harris, J., Bruemmer, B., Archer, S. L., \& Van Horn, L. (2006). Publishing nutrition research: A review of study design, statistical analyses, and other key elements of manuscript preparation, Part 1. Journal of American Diet Association, 106(1), 89-96.

Brown, H. D. (2001). Teaching by principles: An interactive approach to language pedagogy. New York: Longman.

Bryman, A., \& Cramer, D. (1998). Quantitative data analysis with SPSS for windows: A guide for social scientists. London: Routledge.

Burns, M., \& Lawrie, J. (2015). Where it matters most: Quality professional development for all teachers. New York, NY: Interagency Network for Education in Emergences.

Commeyras, M., \& Inyega, H. N. (2007). An integrative review of teaching reading in Kenyan primary schools. Reading Research Quarterly, 42(2), 258-281. doi:10.1598/RRQ.42.2.3

County Government of Vihiga. (2018). County integrated development plan 2018-2022. Nairobi: Kenya Literature Bureau.

Cox, R. (2009). How to teach comprehension reading learners? Retrieved on 23/4/19 from http://ezinearticles.com

Dubeck, M. M., Jukes, M. C. H., \& Okello, G. (2012). Early primary literacy instruction in Kenya. Comparative Education Review, 56(1), 48-68. Retrieved from https://doi.org/10.1086/660693

Finney, S. (2013). Independent reading activities that keep kids learning while you teach small groups. New York: Scholastic Professional Books.

Gathumbi, A. W. (2008). The process of developing English literacy norms. In T. Groenewegen, (Ed.). Benchmarks for English language education. Nairobi: Phoenix Publishers.

Goodman, K. (1967). Reading: A psycholinguistic guessing game. Journal of the Reading Specialist, 6, 126-135.

Grabe, W. (1988). Reassessing the term interactive. In P. L. Carrell, J. Devine, and D. E. Eskey (Eds.), Interactive approaches to second language reading. Cambridge: Cambridge University Press.

Harmer, J. (1983). The practice of English language teaching. New York: Longman.

Hébert, C. (2017). What do we really know about the edTPA? Research, PACT, and packaging a local teacher performance assessment for national use. The Educational Forum, 81(1), 68-82. doi:10.1080/00131725.2016.1242680

Hibbing, A. N., \& Rankin-Erickson, J. L. (2003). A picture is worth a thousand words: Using visual images to improve comprehension for middle school struggling readers. The Reading Teacher, 56(8), 758-770.

Hudson, T. (2007). Teaching second language reading. Oxford: Oxford University Press.

Isutsa, E. L. (2011). Determinants of performance of English-language among public primary schools in Matuga Kwale, Kenya. Retrieved

from https://ir-library.ku.ac.ke/bitstream/handle/123456789/14467/Determinants\%20of\%20performance\%20of\%20English-languag e\%20among\%20public\%20primary\%20schools\%20in\%20Matuga $\% 20$ Kwale $\% 2 c \% 20$ Kenya.pdf?sequence=1\&isAllowed=y

Kathuri, M. W. (2014). Factors influencing performance in Kenya certificate of primary education examination in public primary schools in Kairuri Zone, Embu North District, Kenya (Unpublished MA thesis, School of Continuing and Distance Education, University of Nairobi).

Kenya National Examinations Council (KNEC). (2011-2014). The Years 2010-2013 Kenya certificate of primary education examination reports. Nairobi, Kenya: KNEC.

Lubliner, S. (2005). The effects of comprehensive vocabulary instruction on Title I students' metacognitive word-learning skills and reading comprehension. Journal of Literacy Research, 37(2), 163-200.

Makokha, R. N., \& Wanyonyi, K. W. (2015). The utilization of instructional resources in teaching Kiswahili poetry in secondary schools in Kenya. International Journal of Academic Research in Business and Social Sciences, 5(8), 10-18.

Mose, N. P. (2017). Language-in-education policy in Kenya: Intention, interpretation, implementation. Nordic Journal of African Studies, 26(3), 215-230.

Nachmias, C. F., \& Nachmias, D. (1996). Research methodology in social sciences (5th ed.). London: Arnold.

National Reading Panel. (2013). National assessment of educational progress, various years, 1992-2013 mathematics and reading assessments. Washington, DC: US Department of Education. 
Nur, A. H., \& Ahmad, D. (2017). Improving students' reading skill through interactive approach at the first grade of SMAN 1 Mare, Bone. Journal of Language and Learning, 3(1), 44-56.

Oczkus, L. (2013). Reciprocal teaching: Powerful hands-on comprehension strategy. The Utah Journal of Literacy, 16(1), 34-38.

Oluoch, E. A. (2017). Language of instruction in Kenya: Focus on lower primary in schools in rural areas. International Journal of Education, Learning and Development, 5(1), 17-23.

Ongatoh, P. M. (2017). Institutional factors influencing pupils' performance at Kenya certificate of primary education level in Matungu Sub-County, Kakamega County (Unpublished Master of Educational Administration thesis, University of Nairobi).

Palani, K. K. (2012). Promising reading habits and creating literate social. International Reference Research Journal, $3(2), 91$.

Palincsar, A. S., Spiro, R., \& Magnusson, S. (2013). Investigating the feasibility of scaling up effective reading comprehension instruction using innovative video case based hypermedia. National Science Foundation. Retrieved from https://webcache.googleusercontent.com/search?q=cache:Vug5mWlskx4J:https://www.nsf.gov/awardsearch/showAward\%3 FAWD_ID $\% 3 D 0343578+\& \mathrm{~cd}=1 \& \mathrm{hl}=\mathrm{zh}-\mathrm{CN} \& \mathrm{ct}=\mathrm{clnk} \& \mathrm{gl}=\mathrm{us}$

Pardhan, A., \& Juma, A. (2011). Early childhood education and development teacher guide. Karachi Pakistan: Agha Khan University Institute for Education Development.

Polit, D. F., \& Beck, C. T. (2006). The content validity index: Are you sure you know what's being reported? Critique and recommendations. Research in Nursing \& Health, 29(5), 489-497.

Pressley, M., \& Gaskins, I.W. (2006). Metacognitively competent reading comprehension is constructively responsive reading: How can such a reading be developed in students? Metacognition and Learning, 1(1), 99-113.

Redfern, A., \& Edwards, V. (2007). The world in a classroom: Language in education in Britain and Canada. Clevedon: Multilingual Matters.

Ritter, N. L. (2010). Understanding a widely misunderstood statistic: Cronbach's $\alpha$. Houston, TX: Texas A \& M University.

Rokhsari, S. (2012). An investigation of reading strategies used by Iranian EFL intermediate readers. Journal of Academic and Applied Studies, 2(8), 1-21.

Roy-Campbell, Z. M. (2014). Teaching English as a "second language" in Kenya and the United States: Convergences and divergences. Global Education Review, 2(2), 84-97.

Sharpe, S. (2013). Interactive theory of reading to practice. Knowledge Nugget, EDU 587.01. Retrieved from https://prezi.com/vfbkrdrpmn5n/interactive-theory-of-reading-to-practice/

Smith, F. (2009). The role of prediction in reading achievement. Elementary English, 52(3), 305-311.

Symmons, J. (2013). Solomon four-group design [Permalink]. Retrieved from http://www.janetsymmons.ca/solomen-four-group-design

Uwezo. (2012). Literacy and numeracy across East Africa: Are our children learning? Nairobi: Uwezo.

Vries, M. D. (2011). Professional development for primary teachers in science and technology: The Dutch Vtb-Pro Project in an international perspective. Rotterdam: Sense.

Waller, R., \& Barrentine, S. J. (2015). Rural elementary teachers and place-based connections to text during reading instruction. Journal of Research in Rural Education, 30(7), 1-13.

Wong, P. W. (2014). A snapshot on qualitative research methods. Educational Research and Reviews, 9(5), 130-140.

Yan, D. (2002). Application of interactive approach to the teaching of English reading in college. Retrieved from https://pdfs.semanticscholar.org/4e54/2aaab038cde327b80fb6b768e2388e690ca0.pdf 